(2) Open Access Full Text Article

\title{
Intravenous iron monotherapy for the treatment of non-iron-deficiency anemia in cancer patients undergoing chemotherapy: a pilot study
}

This article was published in the following Dove Press journal:

Drug Design, Development and Therapy

29 August 2013

Number of times this article has been viewed

\author{
Hikmat Abdel-Razeq' \\ Salah Abbasi' \\ lyad Saadi' \\ Rana Jaber ${ }^{2}$ \\ Hazem Abdelelah' \\ 'Department of Internal Medicine, \\ ${ }^{2}$ Department of Pharmacy, King \\ Hussein Cancer Center, Amman, \\ Jordan
}

\begin{abstract}
Background: Anemia in patients with cancer who are undergoing active therapy is commonly encountered and may worsen quality of life in these patients. The effect of blood transfusion is often temporary and may be associated with serious adverse events. Erythropoiesis-stimulating agents are not effective in $30 \%-50 \%$ of patients and may have a negative effect on overall survival.
\end{abstract}

Aims: To assess the efficacy and feasibility of intravenous iron therapy in patients with cancer who have non-iron-deficiency anemia and who are undergoing treatment with chemotherapy without the use of erythropoiesis-stimulating agents.

Methods: Adult patients with solid cancers and non-iron-deficiency anemia were included. Ferric sucrose at a dose of $200 \mathrm{mg}$ was given in short intravenous infusions weekly for a total of 12 weeks. Hemoglobin level was measured at baseline, every 3 weeks, and 2 weeks after the last iron infusion (week 14). Adverse events related to intravenous iron were prospectively reported.

Results: Of 25 patients included, 19 (76.0\%) completed at least three iron infusions and $14(56.0 \%)$ finished the planned 12 weeks of therapy. The mean hemoglobin level of the 25 patients at baseline was $9.6 \mathrm{~g} / \mathrm{dL}$ (median, $9.9 \mathrm{~g} / \mathrm{dL}$; range, $6.9 \mathrm{~g} / \mathrm{dL} 10.9 \mathrm{~g} / \mathrm{dL}$ ). The mean change in hemoglobin level for the 15 patients who completed at least 9 treatments was $1.7 \mathrm{~g} / \mathrm{dL}$ (median, $1.1 \mathrm{~g} / \mathrm{dL}$; range, $-1.9 \mathrm{~g} / \mathrm{dL}$ to $3.2 \mathrm{~g} / \mathrm{dL}$ ); it reached $2.1 \mathrm{~g} / \mathrm{dL}$ (median, $1.3 \mathrm{~g} / \mathrm{dL}$; range, $-0.2 \mathrm{~g} / \mathrm{dL}$ to $4.6 \mathrm{~g} / \mathrm{dL} ; P=0.0007$ ) for the 14 patients who completed all 12 weekly treatments. Five $(20.0 \%)$ patients were transfused and considered as treatment failures. No treatment-related adverse events were reported.

Conclusion: Intravenous iron treatment alone is safe and may reduce blood transfusion requirements and improve hemoglobin level in patients with cancer who are undergoing anticancer therapy. Further randomized studies are needed to confirm these findings.

Keywords: anemia, cancer, chemotherapy, intravenous iron, transfusion

\section{Introduction}

Anemia is a common complication of cancer and its treatment. It occurs in more than $50 \%$ of patients and may reach $90 \%$ in certain types of cancers, especially in patients undergoing chemotherapy and/or radiation therapy. ${ }^{1}$

Anemia is defined as an inadequate circulating level of hemoglobin ( $\mathrm{Hb})$ $(\mathrm{Hb}<12 \mathrm{~g} / \mathrm{dL})$ and may arise as a result of the underlying disease, bleeding, poor nutrition, chemotherapy, or radiation therapy. Preliminary studies suggest that survival and loco-regional control after radiation therapy, especially in head and neck cancers, may be compromised by anemia. ${ }^{2-4}$
Correspondence: Hikmat Abdel-Razeq Department of Internal Medicine, Section of Hematology and Medical Oncology,

King Hussein Cancer Center,

Amman II I94, Jordan

Tel +96265300460

Email habdelrazeq@khcc.jo 
Anemia often worsens symptoms such as fatigue, weakness, and dyspnea, and thus may have a negative effect on quality of life (QOL) and performance status in patients with cancer. Thus, to improve physical functioning, QOL, and prognosis in patients with cancer, it would be reasonable to take a proactive approach in identifying populations who need treatment for cancer-associated anemia (CAA) and provide timely management.

Blood transfusion is an effective way to replace depleted $\mathrm{Hb}$ within a short period, but the effect is, unfortunately, temporary and can cause serious adverse risks and increased mortality. In randomized clinical trials in patients with CAA, erythropoiesis-stimulating agents (ESAs) produced significant increases in $\mathrm{Hb}$ level, decreased transfusion requirements, and improved QOL..$^{5-7}$ However, 30\%-50\% of patients do not respond to such agents. In addition, the use of ESAs often causes concern about severe adverse reactions. ${ }^{6,8}$ In several studies, ESAs were found to shorten overall survival time, or time to tumor progression in patients whose $\mathrm{Hb}$ level reached more than $12 \mathrm{~g} / \mathrm{dL}$. These studies included patients with different primary cancers, such as breast, lung, head and neck, cervix, and lymphomas. ${ }^{9-11}$ The lack of response to erythropoietin stimulation in patients with cancer is partly attributed to the functional iron deficiency state, in which the high rate of erythropoiesis exceeds the delivery of usable iron, despite adequate iron stores. ${ }^{12}$ Absolute iron deficiency, in contrast, occurs when iron delivery is impaired because iron stores are depleted (serum ferritin, $<100 \mathrm{ng} / \mathrm{mL}$; transferring saturation, $<20 \%){ }^{13}$ Hepcidin, a peptide hormone produced by the liver, is upregulated in chronic inflammatory states including cancer. Hepcidin inhibits iron transport across cell membranes, thus decreasing the accessibility of stored iron and gastrointestinal absorption of dietary iron, leading to an increased frequency of iron-restricted erythropoiesis. ${ }^{14-16}$

Many randomized trials examined the role of intravenous (IV) iron in addition to ESAs in the treatment of anemia in patients with cancer. Many of these studies showed improvement in ESA response, time to maximal response, reduction in ESA dose, and improvement in QOL parameters (when measured) in favor of the combination over ESAs alone. The observed benefit was independent of baseline iron parameters. ${ }^{17-21}$ One study found a $36 \%$ reduction in the number of patients transfused. ${ }^{21}$

This pilot study assessed the efficacy and feasibility of IV iron monotherapy in patients with cancer who have anemia and who are undergoing treatment with chemotherapy and/or radiation therapy without the use of ESAs.

\section{Patients and methods}

\section{Study design}

Patients received the study treatment for 12 weeks followed by a 4-week follow-up period. Eligible patients were at least 18 years old, about to start a cycle of chemotherapy and/or radiation therapy within 1 week of inclusion, and had a nonmyeloid malignancy, $\mathrm{Hb}$ levels of $11.0 \mathrm{~g} / \mathrm{dL}$ or less, a life expectancy of more than 24 weeks, and an Eastern Cooperative Oncology Group performance status of 0-2. Patients were also required to have a serum ferritin level of $100 \mathrm{ng} / \mathrm{mL}$ or higher or transferrin saturation (TSAT) levels of $15 \%$ or higher and to have received no ESAs or IV iron therapy within 30 days and no oral iron therapy $(27 \mathrm{mg} /$ day or more) within 7 days before enrollment. Patients were excluded for leukoerythroblastic features on blood film, hemolysis, gastrointestinal bleeding, folate or vitamin B12 deficiency, elevated serum ferritin ( $\geq 900 \mathrm{ng} / \mathrm{mL}$ ) or transferrin saturation (TSAT) $(\geq 35 \%)$ levels, pregnancy or lactation, liver dysfunction (grade 2 or higher based on National Cancer Institute Common Toxicity Criteria), renal dysfunction (serum creatinine levels $\geq 2.0 \mathrm{mg} / \mathrm{dL}$ ), active infection requiring systemic antibiotics, personal or family history of hemochromatosis, comorbidities precluding study participation, hypersensitivity to IV iron, red blood cell transfusion within the last 2 weeks, or any investigational agent within 30 days before enrollment. Patients were not allowed to take any vitamin, mineral, or herbal supplements containing $27 \mathrm{mg}$ or more of iron per day or $100 \mathrm{mg}$ vitamin C per day during the study or follow-up period. Blood transfusions were permitted at the primary physician's discretion if $\mathrm{Hb}$ levels decreased to $8 \mathrm{~g} / \mathrm{dL}$ or less, and such patients were considered treatment failures. Changes to the chemotherapy plan were permitted. Written informed consent was provided by all patients before study participation, and the protocol and supporting documents were approved by the institutional review board of King Hussein Cancer Center. The study was conducted in accordance with the Declaration of Helsinki and Good Clinical Practice as contained in the US Code of Federal Regulations that governs the protection of human subjects and the obligations of clinical investigators.

\section{Treatment}

Patients received $200 \mathrm{mg}$ ferric hydroxide sucrose diluted in $100 \mathrm{~mL}$ normal saline and infused over the course of 1 hour weekly for a total of 12 weeks. The first dose was given during the first clinic visit ( \pm 4 days from the initiation of chemotherapy or radiation therapy). TSAT was monitored, 
as protocol mandated withholding iron therapy when TSAT levels were higher than $50 \%$.

\section{Assessment}

At the first clinic visit (week 1; baseline), a blood sample was obtained for laboratory assessments before the study treatment was started. Patients attended weekly clinic visits for treatment and assessment; and returned for follow-up visits at week 14 which included a complete physical examination. Complete blood count and TSAT were done every 3 weeks, and again 2 weeks after last treatment (week 14). Complete laboratory assessment $(\mathrm{Hb}$, serum ferritin, reticulocyte count, transferrin, TSAT, serum iron, total iron binding capacity, red cell indices, white blood cell count with differential, platelet count, and serum chemistries) were done at week 1 and at week 14 (end of study).

Adverse events were assessed at each clinic visit until study completion or withdrawal, and during the 30 days after the last study treatment.

\section{Statistical analysis}

$\mathrm{Hb}$ test results were presented as mean, median, and range through all 12 weeks. The same was done to show the changes of $\mathrm{Hb}$ level every 3 weeks. Comparison between means of $\mathrm{Hb}$ level were made between the baseline $\mathrm{Hb}$ and $\mathrm{Hb}$ levels in the following weeks, using $t$-test. A significance criterion of $P<0.05$ was used in the analysis. All analyses were performed using SAS version 9.1 (SAS Institute Inc, Cary, NC, USA).

\section{Results}

Twenty-five patients (17 women and 8 men) were eligible, consented, and included in the study; their mean age (standard deviation, [SD]) was 56 years (13.0 years). All patients were receiving active chemotherapy, and two were also receiving active radiotherapy. Chemotherapy varied according to the primary cancer and included anthracycline, platinum, taxanes, cyclophosphamide, high-dose ifosfamide, vincristine, vinblastine, bleomycin, and others. Many of the included patients had their chemotherapy treatment as second- or third-line therapy. Patients' characteristics, including age, primary tumor, and active anticancer treatment are summarized in Table 1.

One patient died during the study from his tumor (after week 2), and five patients withdrew from the study because of inconvenience (three after week 3 , and two after week 4). Nineteen $(76.0 \%)$ patients completed a minimum of three treatments, $15(60.0 \%)$ completed nine treatments, and $14(56.0 \%)$ completed all twelve planned weekly treatments.
Table I Characteristics of the 25 patients with cancer who received intravenous iron therapy for non-iron-deficiency anemia

\begin{tabular}{|c|c|c|c|c|}
\hline Patient & Sex & $\begin{array}{l}\text { Age, } \\
\text { years }\end{array}$ & Type of cancer & Treatment \\
\hline I & Male & 65 & Hodgkin's lymphoma & Chemotherapy \\
\hline 2 & Female & 48 & Neuroblastoma & Chemotherapy \\
\hline 3 & Female & 50 & Breast cancer & Chemotherapy \\
\hline 4 & Female & 41 & High grade sarcoma & Chemotherapy \\
\hline 5 & Female & 72 & $\begin{array}{l}\text { Non-small cell lung } \\
\text { cancer }\end{array}$ & Chemotherapy \\
\hline 6 & Female & 57 & Breast cancer & Chemotherapy \\
\hline 7 & Male & 71 & Prostate cancer & Chemotherapy \\
\hline 8 & Male & 62 & Leg leiomyosarcoma & Chemotherapy \\
\hline 9 & Female & 67 & Breast cancer & Chemotherapy \\
\hline 10 & Female & 70 & $\begin{array}{l}\text { Endometrial } \\
\text { adenocarcinoma }\end{array}$ & Chemotherapy \\
\hline II & Female & 50 & Uterine sarcoma & Chemotherapy \\
\hline 12 & Male & 56 & Bladder cancer & Chemotherapy \\
\hline 13 & Male & 77 & Colon cancer & Chemotherapy \\
\hline 14 & Female & 27 & $\begin{array}{l}\text { Neuroendocrine } \\
\text { tumor }\end{array}$ & Chemotherapy \\
\hline 15 & Female & 33 & Osteosarcoma & Chemotherapy \\
\hline 16 & Female & 61 & Breast cancer & Chemotherapy \\
\hline 17 & Female & 44 & Ewing sarcoma & Chemotherapy \\
\hline 18 & Male & 54 & Renal cell carcinoma & $\begin{array}{l}\text { Sunitinib and } \\
\text { radiotherapy }\end{array}$ \\
\hline 19 & Female & 66 & $\begin{array}{l}\text { Uterine } \\
\text { leiomyosarcoma }\end{array}$ & Chemotherapy \\
\hline 20 & Female & 55 & Breast cancer & Chemotherapy \\
\hline 21 & Female & 53 & Gastric cancer & Chemotherapy \\
\hline 22 & Male & 66 & Rectal cancer & $\begin{array}{l}\text { Chemotherapy } \\
\text { and radiotherapy }\end{array}$ \\
\hline 23 & Female & 69 & Breast cancer & Chemotherapy \\
\hline 24 & Male & 51 & $\begin{array}{l}\text { Desmoplastic } \\
\text { round cell }\end{array}$ & Chemotherapy \\
\hline 25 & Female & 31 & Breast cancer & Chemotherapy \\
\hline
\end{tabular}

As seen in Table 2, the mean $\mathrm{Hb}$ level of the 25 patients at baseline was $9.6 \mathrm{~g} / \mathrm{dL}$ (median, $9.9 \mathrm{~g} / \mathrm{dL}$; range, $6.9 \mathrm{~g} / \mathrm{dL}-10.9 \mathrm{~g} / \mathrm{dL}$ ). For the 15 patients who completed at least nine treatments, the mean change in their $\mathrm{Hb}$ level was $1.7 \mathrm{~g} / \mathrm{dL}$ (median, $1.1 \mathrm{~g} / \mathrm{dL}$; range, $-1.9 \mathrm{~g} / \mathrm{dL}$ to $3.2 \mathrm{~g} / \mathrm{dL}$ ). For the 14 patients who completed the whole treatment period (12 weeks), the mean $\mathrm{Hb}$ level change was $2.1 \mathrm{~g} / \mathrm{dL}$

Table 2 Means and medians of hemoglobin levels (g/dL) of the 25 patients with cancer

\begin{tabular}{llll}
\hline & Patients, $\mathbf{n}$ & $\begin{array}{l}\text { Mean } \\
\text { g/dL (SD) }\end{array}$ & $\begin{array}{l}\text { Median g/dL } \\
\text { (minimum, } \\
\text { maximum) }\end{array}$ \\
\hline Baseline (week I) & 25 & $9.6(1.06)$ & $9.9(6.90,10.9)$ \\
Week 3 & 19 & $10.5(1.28)$ & $10.7(6.80,12.1)$ \\
Week 6 & 15 & $10.5(1.12)$ & $10.5(9.10,12.0)$ \\
Week 9 & 15 & $11.3(1.37)$ & $11.55(8.90,13.2)$ \\
Week 12 & 14 & $11.7(1.22)$ & $11.35(9.80,13.7)$ \\
\hline
\end{tabular}

Abbreviations: $\mathrm{n}$, number; $\mathrm{SD}$, standard deviation. 
(median, $1.3 \mathrm{~g} / \mathrm{dL}$; range, $-0.2 \mathrm{~g} / \mathrm{dL}$ to $4.6 \mathrm{~g} / \mathrm{dL} ; P=0.0007$ ). Eight (42.1\%) of the 19 patients who completed at least three iron infusions had a more than $1 \mathrm{~g} / \mathrm{dL}$ increase in their $\mathrm{Hb}$ level. Hemoglobin level changes for the 14 patients who completed twelve iron infusions are shown in Figure 1.

No IV iron-related adverse events were reported among patients during the study or the follow-up period.

TSAT was monitored during the study period, and no patients had TSAT levels increase to more than 50\%. The highest ferritin level among patients who completed at least nine IV iron treatments was $1,170 \mathrm{ng} / \mathrm{mL}$; the mean level at the end of study period for the whole group was $379 \mathrm{ng} / \mathrm{mL}$.

Five $(20.0 \%)$ patients received blood transfusions and were considered treatment failures (three after week 3, transfused at $\mathrm{Hb}$ levels of $6.9 \mathrm{~g} / \mathrm{dL}, 7.8 \mathrm{~g} / \mathrm{dL}$, and $5.4 \mathrm{~g} / \mathrm{dL}$; one after week 4, transfused at an $\mathrm{Hb}$ level of $8.2 \mathrm{~g} / \mathrm{dL}$; and one after week 9, transfused at an $\mathrm{Hb}$ level of $7.2 \mathrm{~g} / \mathrm{dL}$ ). The decision for transfusion was made by the primary treating physician.

\section{Discussion}

Anemia is extremely common in patients with cancer. Low $\mathrm{Hb}$ levels are associated with diminished QOL and possibly decreased overall survival. ${ }^{2}$ Successful treatment of anemia has undeniable benefits for patients, often yielding dramatic symptomatic improvement. Although the role of ESAs is well-established in treating CAA, big concerns were recently raised about the negative effect of ESAs on survival in some patients with cancer. ${ }^{9-11}$ Concerns about the risk for thromboembolism in patients with cancer with higher $\mathrm{Hb}$ levels who are receiving ESA were also addressed in many trials. ${ }^{22,23}$ In addition, the possible immunosuppressive effects of blood product transfusions that may have relevance to neoplasia progression were addressed before. ${ }^{24,25}$
In our pilot study, we tested the feasibility of using iron supplementation alone to treat anemia in patients with cancer who are undergoing chemotherapy without the use of ESAs or blood transfusion, which could be a valid alternative, especially for patients with curable cancers.

Oral iron is easier to administer and relatively inexpensive, but low patient adherence, poor enteral absorption, and poor tolerance because of a wide range of troublesome gastrointestinal adverse effects limit its overall effectiveness. ${ }^{26}$ Anemia of chronic disease may occur in patients with cancer and is associated with an increase in hepcidin levels, which decreases oral iron absorption and bone marrow iron use, negating any possible effect of regular doses of oral iron. ${ }^{15}$

IV iron therapy significantly improves response to epoetin alfa when compared with oral iron or no iron in anemic patients with cancer who are receiving chemotherapy. ${ }^{17-21}$ Oral iron supplements with ESAs showed no significant benefit over ESAs alone in treating CAA. ${ }^{21}$

Sodium ferric gluconate and iron sucrose appear to have more favorable safety profiles over iron dextran. A large prospective safety comparison trial failed to show serious anaphylactoid reactions, ${ }^{27}$ which is confirmed in our study, in which no patients developed reactions and no patients withdrew from the study because of adverse effects.

Given that the mean $\mathrm{Hb}$ increase using ESAs with IV iron in one large controlled trial was $2.4 \mathrm{~g} / \mathrm{dL},{ }^{21}$ the results obtained in our study are clinically significant. These findings should be further confirmed and better assessed in larger studies, in which questions such as the optimal timing of IV iron therapy with respect to chemotherapy and the optimal total dose of IV iron should be determined.

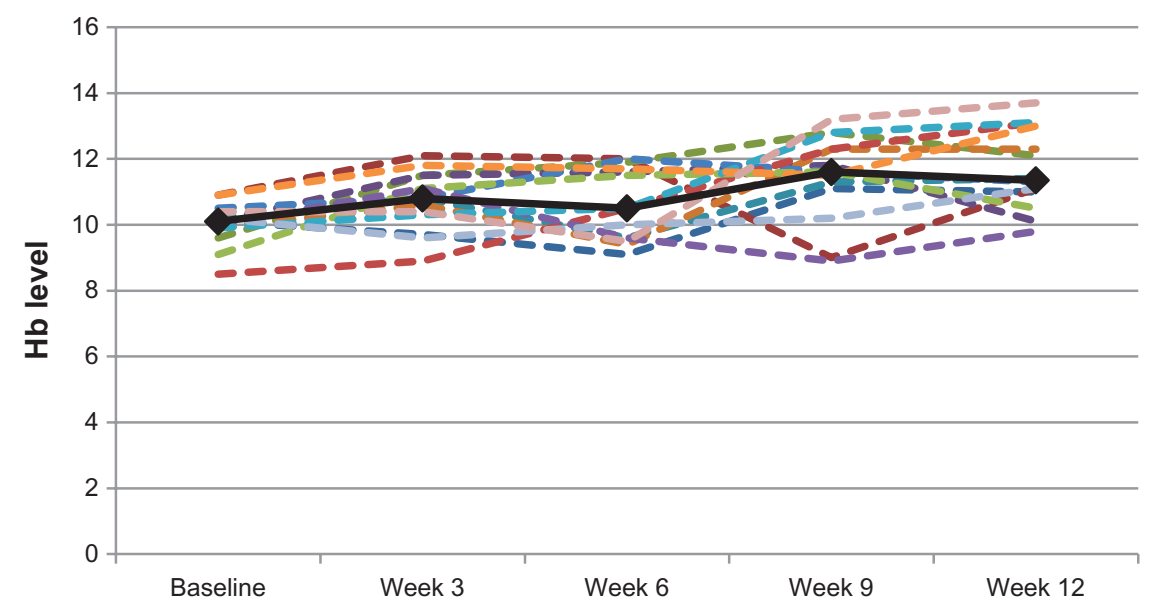

Figure I Hemoglobin $(\mathrm{Hb})$ level changes for the 14 patients who completed 12 iron infusions (dotted lines) and their mean hemoglobin level change (solid line). 
The use of IV iron monotherapy was recently reviewed by a group in Germany that studied the use of ferric carboxymaltose to replace ESA and blood transfusions as a treatment for CAA. Iron-deficient patients treated with ferric carboxymaltose alone $(\mathrm{n}=233)$ had a median of $1.4 \mathrm{~g} / \mathrm{dL}$ increase in hemoglobin levels compared with those receiving additional treatment with ESAs ( $\mathrm{n}=46$; median, $1.6 \mathrm{~g} / \mathrm{dL})$. Our study, however, is peculiar in using iron therapy in a non-iron-deficiency state. ${ }^{28}$

Iron overload after IV iron therapy, with potential concerns about the risk of developing secondary cancers and infection, might be raised. The highest serum ferritin level in the present study in patients who completed at least 9 weeks of IV iron therapy was $1,170 \mathrm{ng} / \mathrm{mL}$. Most of the literature addressing cancer and infections in iron-overloaded patients comes from patients with hemochromatosis or patients who are undergoing hemodialysis. Published reviews report an increase in hepatocellular carcinoma only in patients with hemochromatosis after they develop cirrhosis. ${ }^{29}$ Similarly data supporting the association between IV iron therapy and higher infection rate are weak and not well-supported. ${ }^{30} \mathrm{In}$ fact, anemia itself is a risk factor for infections in patients receiving hemodialysis. ${ }^{31} \mathrm{~A}$ multivariate analysis of associations between iron and mortality in more than 58,000 patients receiving hemodialysis reported no increased death rate from serum ferritin levels as high as $1,200 \mathrm{ng} / \mathrm{mL} .^{30}$

The increasing cost of therapy in patients with cancer is of grave concern, which could be an additional benefit of IV iron over the use of ESAs in such patients.

To further address many of the questions raised, our team is planning a bigger trial for IV iron in patients with cancer who have anemia to confirm the results discussed in this pilot trial. In addition, we will be looking into predictors of response to IV iron, such as serum hepcidin level.

\section{Conclusion}

IV iron therapy alone is safe and may be effective in improving $\mathrm{Hb}$ levels in patients with cancer who are undergoing active anticancer therapy. Further randomized trials are needed to address many of the questions raised in our pilot study.

\section{Disclosure}

The authors report no conflicts of interest in this work.

\section{References}

1. Henry DH. Supplemental iron: a key to optimizing the response of cancer-related anemia to rHuEPO? Oncologist. 1993(4):275-278.
2. Knight K, Wade S, Balducci L. Prevalence and outcomes of anemia in cancer: a systematic review of the literature. Am J Med. 2004; 116(Supp1 7A):11S-26S.

3. Cella D, Kallich J, McDermott A, Xu X. The longitudinal relationship of hemoglobin, fatigue and quality of life in anemic cancer patients: results from five randomized clinical trials. Ann Oncol. 2004;15(6): 979-986.

4. Harrison LB, Chadha M, Hill RJ, Hu K, Shasha D. Impact of tumor hypoxia and anemia on radiation therapy outcomes. Oncologist. 2007(6): 492-508.

5. Demetri GD, Kris M, Wade J, Degos L, Cella D. Quality-of-life benefit in chemotherapy patients treated with epoetin alfa is independent of disease response or tumor type: results from a prospective community oncology study. Procrit Study Group. J Clin Oncol. 1998;16(10): $3412-3425$.

6. Gabrilove JL, Cleeland CS, Livingston RB, Sarokhan B, Winer E, Einhorn LH. Clinical evaluation of once-weekly dosing of epoetin alfa in chemotherapy patients: improvements in hemoglobin and quality of life are similar to three-times-weekly dosing. J Clin Oncol. 2001;19(11): 2875-2882.

7. Littlewood TJ, Bajetta E, Nortier JW, Vercammen E, Rapoport B; Epoetin Alfa Study Group. Effects of epoetin alfa on hematologic parameters and quality of life in cancer patients receiving nonplatinum chemotherapy: results of a randomized, double-blind, placebocontrolled trial. J Clin Oncol. 2001;19(11):2865-2874.

8. Glaspy J, Bukowski R, Steinberg D, Taylor C, Tchekmedyian S, Vadhan-Raj S. Impact of therapy with epoetin alfa on clinical outcomes in patients with nonmyeloid malignancies during cancer chemotherapy in community oncology practice. Procrit Study Group. J Clin Oncol. 1997;15(3):1218-1234.

9. Henke M, Laszig R, Rübe C, et al. Erythropoietin to treat head and neck cancer patients with anaemia undergoing radiotherapy: randomised, double-blind, placebo-controlled trial. Lancet. 2003;362(9392): $1255-1260$.

10. Leyland-Jones B; BEST Investigators and Study Group. Breast cancer trial with erythropoietin terminated unexpectedly. Lancet Oncol. 2003;4(8):459-460.

11. Bohlius J, Langensiepen S, Schwarzer G, et al. Recombinant human erythropoietin and overall survival in cancer patients: results of a comprehensive meta-analysis. J Natl Cancer Inst. 2005;97(7): 489-498.

12. Macdougall IC. Strategies for iron supplementation: oral versus intravenous. Kidney Int Suppl. 1999;69:S61-S66.

13. KDOQI. KDOQI Clinical Practice Guideline and Clinical Practice Recommendations for anemia in chronic kidney disease: 2007 update of hemoglobin target. Am J Kidney Dis. 2007;50(3):471-530.

14. Cazzola M, Mercuriali F, Brugnara C. Use of recombinant human erythropoietin outside the setting of uremia. Blood. 1997;89(12): $4248-4267$.

15. Weiss G, Goodnough LT. Anemia of chronic disease. $N$ Engl J Med. 2005;352(10):1011-1023.

16. Andrews NC. Anemia of inflammation: the cytokine-hepcidin link. J Clin Invest. 2004;113(9):1251-1253.

17. Hedenus M, Birgegård G, Näsman $P$, et al. Addition of intravenous iron to epoetin beta increases hemoglobin response and decreases epoetin dose requirement in anemic patients with lymphoproliferative malignancies: a randomized multicenter study. Leukemia. 2007;21(4): 627-632.

18. Pedrazzoli P, Farris A, Del Prete S, et al. Randomized trial of intravenous iron supplementation in patients with chemotherapy-related anemia without iron deficiency treated with darbepoetin alpha. $J$ Clin Oncol. 2008;26(10):1619-1625.

19. Bastit L, Vandebroek A, Altintas S, et al. Randomized, multicenter, controlled trial comparing the efficacy and safety of darbepoetin alpha administered every 3 weeks with or without intravenous iron in patients with chemotherapy-induced anemia. J Clin Oncol. 2008;26(10): 1611-1618. 
20. Auerbach M, Silberstein PT, Webb RT, et al. Darbepoetin alfa 300 or $500 \mu \mathrm{g}$ once every 3 weeks with or without intravenous iron in patients with chemotherapy-induced anemia. Am J Hematol. 2010;85(9): 655-663.

21. Henry DH, Dahl NV, Auerbach M, Tchekmedyian S, Laufman LR. Intravenous ferric gluconate significantly improves response to epoetin alfa versus oral iron or no iron in anemic patients with cancer receiving chemotherapy. Oncologist. 2007;12(2):231-242.

22. Steensma DP. Management of anemia in patients with cancer. Curr Oncol Rep. 2004;6(4):297-304.

23. Wun T, Law L, Harvey D, Sieracki B, Scudder SA, Ryu JK. Increased incidence of symptomatic venous thrombosis in patients with cervical carcinoma treated with concurrent chemotherapy, radiation, and erythropoietin. Cancer. 2003;98(7):1514-1520.

24. Shao W, Edelman LS, Sullivan DJ, Nelson EW, Shelby J. Long-term cytokine alterations following allogeneic blood transfusion. J Investig Med. 1998;46(4):161-167.

25. Santin AD, Bellone S, Parrish RS, et al. Influence of allogeneic blood transfusion on clinical outcome during radiotherapy for cancer of the uterine cervix. Gynecol Obstet Invest. 2003;56(1):28-34.
26. Fishbane S, Frei GL, Maesaka J. Reduction in recombinant human erythropoietin doses by the use of chronic intravenous iron supplementation. Am J Kidney Dis. 1995;26(1):41-46.

27. Fishbane S. Safety in iron management. Am J Kidney Dis. 2003; 41(Suppl 5):18-26.

28. Steinmetz T, Tschechne B, Harlin O, et al. Clinical experience with ferric carboxymaltose in the treatment of cancer- and chemotherapyassociated anaemia. Ann Oncol. 2013;24(2):475-482.

29. Kowdley KV. Iron, hemochromatosis, and hepatocellular carcinoma. Gastroenterology. 2004;127(5 Suppl 1):S79-S86.

30. Besarab A, Frinak S, Yee J. An indistinct balance: the safety and efficacy of parenteral iron therapy. J Am Soc Nephrol. 1999;10(9):2029-2043.

31. Kalantar-Zadeh K, Regidor DL, McAllister CJ, Michael B, Warnock DG. Time-dependent associations between iron and mortality in hemodialysis patients. J Am Soc Nephrol. 2005;16(10): 3070-3080.
Drug Design, Development and Therapy

\section{Publish your work in this journal}

Drug Design, Development and Therapy is an international, peerreviewed open-access journal that spans the spectrum of drug design and development through to clinical applications. Clinical outcomes, patient safety, and programs for the development and effective, safe, and sustained use of medicines are a feature of the journal, which

\section{Dovepress}

has also been accepted for indexing on PubMed Central. The manuscript management system is completely online and includes a very quick and fair peer-review system, which is all easy to use. Visit http://www.dovepress.com/testimonials.php to read real quotes from published authors.

Submit your manuscript here: http://www.dovepress.com/drug-design-development-and-therapy-journal 